\title{
ANÁLISE DOCUMENTAL E CONTEXTO DE DESENVOLVIMENTO: ESTATUTOS DE UMA INSTITUIÇÃO DE PROTEÇÃO À INFÂNCIA DE SALVADOR, BAHIA*
}

\author{
ARCHIVAL RESEARCH AND DEVELOPMENTAL CONTEXT: \\ ANALYSIS OF STATUTES OF A CHILD CARE INSTITUTION \\ FROM SALVADOR, BAHIA
}

Roberta BORRIONE Antonio Marcos CHAVES ${ }^{* *}$

\begin{abstract}
RESUMO
Este estudo busca evidenciar as possibilidades de interface entre Psicologia e História, ao analisar documentos de uma instituição de auxílio e proteção à infância abandonada do século XIX - Asilo dos Expostos da Santa Casa de Misericórdia de Salvador - como forma de interpretação do contexto de desenvolvimento. Essa instituição foi estabelecida com o objetivo de dar abrigo, proteção, educação e também dar conformação às crianças abandonadas às normas sociais. A análise de dois estatutos do referido estabelecimento, datados de 1863 e 1914, permite a compreensão do significado de criança abandonada nesses momentos e do contexto de desenvolvimento, no qual estava inserida, já que os documentos são produtos elaborados por uma sociedade para transmitir imagens e valores socialmente aceitos. Esta análise elucidou uma gradativa mudança da preocupação social com a criança abandonada. Passou-se da preocupação com a provisão dos meios imediatos de sobrevivência para a promoção de educação profissional e reinserção social das crianças, baseadas em preceitos filantrópicos e médico-higienistas.
\end{abstract}

Palavras-chave: infância, análise documental, Asilo dos Expostos, análise sócio-histórica.

\footnotetext{
(*) Agradecimentos à Santa Casa de Misericórdia de Salbador (Bahia), pelal permissão de pesquisar em seu arquivo histórico, e a Prof. Dra. Sônia Maria Guedes Gondim professora do PPGPSI - UFBA, responsável pela revisão deste artigo e pela disciplina Métodos Qualitativos, cujo artigo foi fruto de trabalho de conclusão da mesma, com apoio da CAPES.

(*) Mestranda em Psicologia da Universidade Federal da Bahia (PPGPSI - UFBA). Endereço para correspondência: R. Mangalô, 289/101 - Colina A, Patamares - Salvador/BA - CEP 41680-380 - E-mail: borrione@ufba.br

(*) Professor Doutor do Programa de Pós-Graduação da Universidade Federal da Bahia (PPGPSI - UFBA). Endereço para Correspondência: Av. Otávio Mangabeira, 11881, M4 ap 06 - Piatã - Salvador/BA - CEP 41650-000 - E-mail: amchaves@ufba.br
} 


\begin{abstract}
This research attempts to evidence an interface between psychology and history, through the analysis of documents from a nineteenth-century child care institution for abandoned children in Salvador, Bahia - Asilo dos Expostos of the Holy House of Mercy - as a way of interpretation of the developmental context of the time. This institution was devised to provide shelter, protection, education, and a social upbringing to abandoned children. The analysis of two statutes of the institution in case (dated 1863 and 1914) - as products constructed by a specific society in order to ascertain socially accepted values - allows for a comprehension about the meaning of the abandoned child and the developmental context in which s/he was involved at the time in question. This analysis elucidates a gradual change of social concern for the abandoned child, from one of providing an immediate means of survival to one of assuring professional education and social reintegration, based on philanthropic and hygienic concepts.
\end{abstract}

Key-words: childhood, document analysis, Asilo dos Expostos, socialhistorical analysis.

Este estudo busca evidenciar as possibilidades de interface entre Psicologia e História, ao analisar documentos referentes a uma instituição de auxílio e proteção à infância abandonada do século XIX, como forma de interpretação do contexto de desenvolvimento.

A História permite a elucidação da processualidade de eventos e fatos, contextualizados em momentos específicos, cujo desenvolvimento ocorre no interior de uma duração relativamente autônoma, ou seja, com distintos níveis de temporalidade e de ritmos, cuja compreensão, de acordo com Cardoso e Brignoli (1990), não pode ser atingida por meio da linearidade ou de divisões temporais de datas importantes, décadas e séculos (divisões primordialmente didáticas). Esta ocorre apenas via uma análise profunda dos diferentes tempos possíveis e por meio de uma busca de interconexões ou divergências que permeiam a criação desses registros. Esta posição foi claramente explicitada por Le Goff (1995), quando afirmou: "A história caminha mais ou menos depressa, porém as forças profundas da história só atuam e se deixam apreender no tempo longo" (p. 45).

O papel da História reside na apreensão das articulações intrinsecamente conectadas e interligadas de um sistema, cuja estrutura possui uma coerência interna de difícil acesso aos indivíduos, por estes partilharem a temporalidade de sua ocorrência. A estrutura desse sistema é formada por traços rigorosos e coerentes de uma realidade socialmente partilhada - como uma totalidade psíquica, que se impõe aos sujeitos inadvertidamente. Sua apreensão é possível devido ao estranhamento diante de uma cultura, via análise histórica de permanências, mudanças e constatação de diferenças irredutíveis entre as culturas, por intermédio da comparação passado versus presente, por exemplo, relatados nos dados óbvios e imutáveis destas culturas, total ou parcialmente mal percebidos, tais como "idéias recebidas ou idéias no ar, lugares-comuns, códigos de conveniência e de moral, conformismos ou proibições, expressões omitidas, impostas ou excluídas dos sentimentos e dos fantasmas" (Ariès, 1995, p. 174). A história, portanto, possibilita a inteligibilidade da particularidade e da originalidade do momento ou da cultura e promove um esboço daquela mentalidade.

A Psicologia, por sua vez, favorece a análise simbólica dos textos, considerados como representação social da realidade de um contexto ético-político, no qual coexistem acordos, tensões e perturbações sociais (Mynaio, 1996). Sua 
abordagem enuncia os elementos inerentes aos processos sociais, às normas de socialização e às práticas discursivas que estão interconectados ao momento.

Nesse sentido, a Psicologia Histórica engloba essas considerações, abordando as transformações históricas, no plano factual. Penna (1980) afirma que "os fatos humanos têm todos uma data e um lugar" (p. 4), são indissociáveis do contexto histórico, no qual foram produzidos, e suas análises - essencialmente qualitativas-ocorrem em perspectiva longitudinal ou temporal.

Os registros históricos constituem fontes de pesquisa, dentre os quais os documentos oficiais de uma instituição - os estatutos, por exemplo - são produzidos "consciente ou inconscientemente pelas sociedades do passado, tanto para impor uma imagem desse passado, quanto para dizer 'a verdade'" (Le Goff, 1995, p. 54). Dependem, destarte, parcialmente da época de sua constituição e representam valores sociais admitidos. Segundo Spink (2000), os documentos são

produtos em tempo e componentes significativos do cotidiano; complementam, completam e competem com a narrativa e a memória. [...] Sua intersubjetividade é produto da interação com um outro desconhecido, porém significativo e freqüentemente coletivo. (p. 126).

Por estarem situados em tempo e refletirem a interação intersubjetiva de interlocutores, constituem práticas discursivas que representam idéias diferentes, saberes, fazeres e múltiplos elementos, conexos ou desconexos, dispostos longitudinalmente, e que denunciam imagens, usos, sentidos e processos humanos.

Nesse sentido, pretende-se advogar a utilização de textos documentais como práticas discursivas de determinado momento sóciohistórico, capazes de elucidar os saberes considerados pertinentes a essa época e, conseqüentemente, o contexto de desenvolvimento defendido que, no presente estudo, se refere a uma instituição de auxílio e proteção à infância abandonada do século XIX (Asilo dos Expostos da Santa Casa da Misericórdia de Salvador).

\section{Sobre a história das instituições de proteção à infância abandonada no Brasil e na Bahia...}

As instituições de proteção à infância surgiram em decorrência de um conjunto de fatores: (1) o surgimento do sentimento de infância e a concepção da infância como um período particular do desenvolvimento da criança, sendo esta um indivíduo (concepção do indivíduocriança) que possui direitos e necessita de cuidados especiais e proteção dos adultos para sua formação (Ariès, 1981); (2) a tentativa de evitar o infanticídio e o aborto, já que o abandono decorria essencialmente de questões financeiras e/ou morais (pobreza e/ou ilegitimidade da criança filha de mães solteiras); (3) o desconforto social e religioso, numa sociedade católica, ao contato com crianças perambulando sozinhas pela cidade ou com os corpos expostos nas ruas, sujeitas às intempéries da natureza e aos ataques dos animais (Marcílio, 1998); (4) a preocupação em evitar a marginalização, a prostituição e a criminalidade das crianças abandonadas (Marcílio, 1996); e, posteriormente, (5) a necessidade de educar, corrigir, disciplinar e controlar as crianças pobres e desamparadas para que se tornassem cidadãos úteis à sociedade.

A Roda dos Expostos de Salvador (Bahia) data de 1726 e foi uma das instituições implantadas com o objetivo de acolher e prover um encaminhamento para a criança recém-nascida abandonada (Marcílio, 1998). Essa assistência fundamentava-se em práticas caritativas, paternalistas e imediatistas, que visavam ao cuidado básico da criança e, especialmente, à salvação da sua alma, via batismo, devido à alta mortalidade. Operava como local de acolhimento de crianças, com rápido envio destas para outras famílias ou para amas-de-leite, que as recebiam para criar em troca de auxílio financeiro. Funcionou no Hospital da Santa Casa de Misericórdia da 
Bahia até 1844, quando foi anexada ao Recolhimento. A contratação de amas-de-leite internas permitiu a estada dos bebês por um período maior na Casa, reduzindo, assim, a busca constante por uma alocação imediata. Já em 1847, foram incorporados novos cômodos à instituição e houve separação das crianças por sexo. Venâncio (1999) afirma que a existência de cômodos específicos para a Casa dos Expostos de Salvador (Bahia), no século XIX, reflete o reconhecimento da importância e do prestígio desse estabelecimento na sociedade, bem como da preocupação em afastar as crianças do contato com os doentes internados nas enfermarias do Hospital.

O acolhimento das crianças nessas instituições, contudo, não Ihes assegurava um futuro próspero. Segundo Marcílio (1996), a criança ainda deveria passar por duas provas: a morte precoce (cuja mortalidade abrangia $65 \%$ a $70 \%$ da população infantil interna) e a criação e sobrevivência até a maioridade.

Durante o século XVIII, a trajetória sob guarda institucional iniciava com o encaminhamento das crianças aos cuidados de amas-deleite por um período de três anos. Essas amas eram mulheres pobres e livres, geralmente, solteiras, mulatas, ex-escravas e agregadas em casas alheias, mas havia também escravas, alugadas por seus amos. A maioria delas cuidava das crianças com desvelo. Havia, contudo, conforme aponta Marcílio (1996), procedimentos fraudulentos no trato das amas com a Casa. Algumas mulheres depositavam seus próprios filhos na Roda, para depois buscá-los, como amas, e receber o pagamento pela criação. Outras escolhiam crianças pardas, para depois vendê-las como escravas, ou escondiam a morte dos bebês para continuar a receber os vencimentos. Findo o período de criação com as amas, essas crianças seguiam para um lar considerado adequado, onde dependiam da condição financeira da família e, freqüentemente, trabalhavam em troca do sustento.

No século XIX, particularmente em Salvador (Bahia), inovou-se (a) ao ser anunciada claramente a alocação do trabalho do/as expostos/as ou a aprendizagem de um ofício; (b) ao ser criado o Asilo dos Expostos, local onde a criança poderia receber alguma forma de educação; e (c) ao ser permitida a saída com o advindo da maioridade - 20 anos (Marcílio, 1996; Marcílio, 1998; Venâncio, 1999). As meninas maiores, nesse caso, podiam pedir o desligamento da casa e assumir a própria vida.

Apesar da reforma do sistema da Roda e da mudança do caráter da instituição, em todo o Brasil, com ênfase nas vantagens do ensino elementar e profissional, houve declínio a partir da segunda metade do século XIX, devido (1) ao surgimento de novas instituições (clínicas pediátricas e orfanatos), que, pela sua existência e funcionalidade, proporcionaram novas formas de enjeitamento das famílias pobres; (2) às melhoras nas condições de vida e nas condições sanitárias das famílias; (3) mas especialmente, à mudança de mentalidade da sociedade, que associou as antigas instituições de assistência infantil aos "símbolos do passado colonial, institutos anacrônicos e preconceituosamente vistos como berços de raças inferiores" (em contexto de crise da escravidão da raça negra/da "gente de cor") (Venâncio, 1999, p. 169).

Surgiram as creches, os jardins-de-infância e as escolas maternais, como novos estabelecimentos de assistência à infância. As creches tinham a função primordial de guardar a criança pobre e abandonada e viabilizar sua sobrevivência (Mattioli, 1994). Os jardins-de-infância constituíram uma alternativa para a educação de crianças de outras camadas sociais (da elite, inclusive), muito embora, no Brasil, seu surgimento, em 1875, esteja relacionado ao atendimento da criança desvalida. Já as escolas maternais representaram - sem sucesso - uma tentativa de modificação do caráter assistencialista das creches, por meio da adoção da filosofia educativa dos jardins-de-infância na educação das crianças desvalidas e, principalmente, dos filhos da classe operária. De qualquer sorte, nunca chegou a existir uma distinção rigorosa dessas instituições ou da nomenclatura utilizada para designá-las, devido a preocupações médico-sanitárias e assistencialistas. Asso- 
ciou-se educação à guarda/sobrevivência da criança.

No início do século XX, as casas da Roda recuperaram certo prestígio, ao modificarem seu funcionamento interno e assemelharem-se aos novos estabelecimentos de abrigo infantil, com a abolição do sistema de amas externas e a utilização do leite em pó, como alimento para os recém-nascidos (Venâncio, 1999). Essas mudanças, contudo, não foram suficientes para manter o funcionamento das instituições que fecharam as portas até 1950 .

\section{Sobre a institucionalização como contexto de desenvolvimento...}

As instituições culturais - em sua constituição - refletem as crenças humanas sobre o comportamento humano, atribuindo-lhe significados institucionalizados e iniciando o processo de socialização dos indivíduos. A sociedade cria matrizes institucionais (instrumentos de nomeação, classificação e socialização, tais como fichas de admissão, expostos/as) - como significados culturais - com a finalidade de impor uma versão particular da realidade e de orientar e controlar os atos dos indivíduos (Bruner, 1997).

Este é o caso dos estatutos que, como documentos oficiais de uma dada instituição, enunciam as normas e regras socialmente aceitas em suas circunvizinhanças e nas relações interpessoais e denunciam a dinâmica oficial proposta. A análise desses estatutos permite, portanto, a apreensão do contexto de desenvolvimento institucional de crianças, via compreensão das suas práticas institucionais, as quais permeavam o relacionamento dos atores sociais.

Essa compreensão é possível, a partir da premissa de que as instituições de reclusão total comprometem a totalidade da vida dos seus integrantes e possibilitam a administração de todos os aspectos da vida psíquica e social dos sujeitos internos, por funcionarem como sistemas fechados, fortemente instituídos e imutáveis, nos quais há o estabelecimento de normas, modelos e códigos com fins de controle (Losicer, 1996). O indivíduo, ao se tornar membro dessa comunidade, "passa a estar sujeito a toda uma série de pressões e coerções sociais informais, implícitas nas obrigações que adquire, já que estas se convertem no caminho para chegar às recompensas" institucionais (Benelli \& CostaRosa, 2002, p. 39).

No contexto institucional, a formação perpassa um processo de normatização do comportamento. Impõe-se um quotidiano preestabelecido de acordo com um sistema de normas e regras de controle e/ou de correção disciplinar do corpo, caracterizado por uma rígida rotina e por espaços de circulação restritos aos limites da instituição, de forma a instrumentalizálo (Chaves, 2002; Foucault, 1999).

Segundo Sawaia (1999), a institucionalização ainda propicia um espaço de abrigo infantil e de não-existência do abandono. Em contrapartida, cria uma inclusão social perversa, já que gera condições sociais de cuidado, proteção e educação desiguais e apenas atende, em seu limite mínimo, a alimentação, o vestuário e o abrigo, por um limitado período de tempo. Não há a oportunidade da participação das crianças nas escolhas e decisões quanto ao seu fazer, especialmente, ao seu fazer futuro; há controle nas formas de ocupação e de estabelecimento de interações e na constituição de vínculos afetivos, que são restritos. Enfim, há a manutenção da condição social prévia da criança.

\section{METODOLOGIA}

O presente estudo busca (1) apreender os significados de infância na Bahia do século XIX, que partilhavam de uma realidade institucional, (2) entender como essa realidade, denunciada nas práticas instituídas e sociais, permeava o contexto de desenvolvimento infantil, via análise documental dos estatutos, e (3) exemplificar sua aplicação para o estudo do desenvolvimento humano.

Para tal, as fontes de dados foram dois estatutos do Asilo dos Expostos da Santa Casa de Misericórdia de Salvador, Bahia, referentes aos anos de 1863 e de 1914. Esses podem 
revelar as normas e regras consideradas socialmente adequadas para a criação e para o convívio com crianças, em dois momentos históricos distintos, proporcionando meios para a (de)composição das realidades vigentes. Devese notar que o primeiro remonta, justamente, ao período da criação do Asilo dos Expostos, como uma instituição independente das demais instituições da Santa Casa, e o segundo, à época de sua reestruturação.

Os Estatutos foram transcritos em sua totalidade. As informações foram codificadas em categorias, segundo a análise qualitativa de conteúdo temática, conforme proposto por Bardin (1994), cujo tema norteador foi a trajetória institucional das crianças, sendo este subdividido em três categorias: formas de ingresso e de saída, políticas educacionais e sistema de controle institucional.

\section{RESULTADOS E DISCUSSÃO}

Os dados revelam progressiva mudança na compreensão da infância abandonada institucionalizada, como pode ser visto na denominação utilizada para falar a respeito das crianças. Em 1863, essas eram chamadas, em ordem decrescente de freqüência, de expostos/as, meninos/as, crianças e rapazes. Já em 1914, aparecem os termos asilados e crianças, quase equiparados, seguidos de educandos/as, menor e exposto (este com apenas uma ocorrência). Inicialmente, portanto, a criança-exposta - merecia cuidados especiais e acompanhamento na sua criação. Concebia-se, parcialmente, a infância como um período particular de desenvolvimento. Prevalecia ainda, contudo, um caráter negativo do abandono, como conseqüência da rejeição dos pais. Preocupava-se primordialmente com a sua sobrevivência e a salvaguarda da sua saúde - em vida - e da sua alma - em morte.

Posteriormente, a criança - asilada ou simplesmente criança - era vista como ser em início da criação, cuja situação de miserabilidade e desproteção, oriunda do abandono, deveria ser remediada. Houve a estruturação de um completo programa educativo, considerando-se a criança enquanto projeto de futuro, que persistiu, foi reelaborado e ressaltado. As idéias da Medicina Higienista se impuseram e a educação das crianças emergiu como fator crucial.

\section{Formas de ingresso e de saída}

A trajetória institucional da criança na Santa Casa de Misericórdia de Salvador (referida, doravante, como Santa Casa ou Casa) iniciavase no momento da sua admissão. Esta ocorria unicamente por meio da Roda.

Imediatamente à entrada, prestavam-se os primeiros cuidados. No caso do estatuto de 1863, estes se referiam à amamentação e ao enfaixamento (procedimento de envolvimento da criança em panos, de forma que sua mobilidade ficava restrita). Posterior a isso, o/a recémexposto/a era entregue a uma ama interna. Neste período, a Roda ainda se encontrava no Recolhimento. Registrava-se a entrada em dois livros específicos, anotando-se qualquer marca de particularidade da recém-chegada criança (sinais naturais ou postos, tais como quantidade e qualidade da roupa e cartas - procedimento mantido em 1914).

Este procedimento indica a preocupação de identificar cada criança e, indiretamente, a prática de pais retornarem à Casa para reaver seus filhos, após melhora financeira ou passado o período crítico de sobrevivência (Marcílio, 1998).

Havia ênfase quanto ao batismo, com exaltação do imediato batizado, especialmente nos casos de perigo de vida e na entrega a uma ama somente após esse fato. Pode-se notar também tanto uma preocupação com a sobrevivência da criança, quanto a incerteza dessa ou do destino dessa criança, após a entrega a uma ama externa. Concebia-se uma efêmera vida e alta mortalidade infantil. A preocupação estava em salvaguardar a alma dos inocentes enjeitados por seus pais.

Os grandes funcionários - os Irmãos - da Casa não só se constituíam em padrinhos em potencial, mas também forneciam o cognome à criança. O nome provinha do Santo do dia da 
exposição e o sobrenome do primeiro provedor do Asilo dos Expostos da Santa Casa de Salvador (Bahia). Pode-se inferir a existência de uma esfera religiosa e afetiva quanto ao acolhimento do bebê. De qualquer sorte, como proposto por Venâncio (1999), a marca original de abandonados/as, ou melhor, de enjeitados/as ou expostos/as acompanhavam-nos/as após sua emancipação, já que seus nomes serviam de identificação pós-institucional e poderiam contribuir para a discriminação.

Já no estatuto de 1914, nota-se uma exaltação da necessidade de identificação da criança, que não apenas era registrada em livro específico, mas também carregava consigo, em seu pescoço, um colar com medalha de identificação. Surgiu o registro civil e mencionou-se corriqueiramente o batismo. Verifica-se a laicificação da assistência, na qual o registro civil se sobrepõe à importância do batismo. Da mesma forma, pode-se também inferir o aumento da sobrevida do bebê.

A trajetória institucional finalizava com a saída (ou "alta definitiva") do/as exposto/as, a interrupção da responsabilidade da Casa pelo cuidado dos/as mesmos/as e o desligamento completo do/a exposto/a.

De forma geral, os procedimentos de finalização da guarda institucional mantiveram-se constantes, salvo particularidades. $O$ desligamento decorria da mudança de estado (via casamento ou obtenção da maioridade) e da transferência para outro estabelecimento, por motivo de continuação da educação técnica ou profissional. Em 1863, findo o tempo convencional para ensino de ofício, havia a alta definitiva. Já em 1914, a própria saída do estabelecimento, independente do motivo, já representava um desligamento, condicionado à assinatura de dois termos - um de responsabilidade (na secretaria da Santa Casa) e outro de tutoria do menor (no Juízo dos Órfãos) - nos quais se transferia a responsabilidade de cuidado da criança à pessoa, de "caráter idôneo", que se dispusesse a tê-lo. Essa saída era até incentivada, quando já se havia recebido a instrução primária, técnica ou profissional e quando os destinos eram casas de particulares ou oficinas confiáveis, as quais se dedicassem a trabalhos profissionais ou industriais.

Outra forma de saída do Asilo decorria da reclamação do/a exposto/a por parte de parentes. Em 1863, os requerimentos eram submetidos à aprovação do Mordomo dos expostos, quanto à sua pertinência, e dependia do pagamento de indenização das despesas realizadas com o/a exposto/a, dispensado em caso de pobreza e probidade comprovada. Nestes casos, ocorria a entrega mediante assinatura de termo, compromisso de provisão da educação primária e de apresentação semestral obrigatória do/a mesmo/a à Mesa da Casa. Já em 1914, o processo - mais simples - dependia apenas da comprovação, por qualquer meio legal em vigor, de ser pai ou parente (ascendente, descendente ou colateral). Não havia menção do pagamento de indenizações com despesas ou acompanhamentos posteriores da criança. Dessa forma, pode-se conceber uma gradativa dessensibilização quanto à preocupação com o destino do/a exposto/a, após a saída institucional.

\section{Políticas Educacionais}

Após a admissão, os estatutos de 1863 e 1914 demonstram trajetórias diferentes.

Em 1863, estava estabelecida uma estada com grande movimentação das crianças (entrega a amas e posterior recolhimento das crianças da guarda das mesmas, entrega para famílias ou instituições profissionalizantes), como disposto por Marcílio (1996). Já em 1914, as crianças permaneciam no Asilo dos Expostos, durante toda a sua estada institucional, salvo exceções.

No primeiro momento, em 1863, a criança era dada à criação de uma ama-de-leite. A seguir, podia retornar ao Asilo ou ser entregue a uma ama de criação. Quando completava seis anos, retornava ao Asilo para a educação primária, acomodada ao gênero da criança, realizada na escola do próprio estabelecimento. As meninas eram educadas de forma a se tornarem boas mães de família e a se habilitarem a passar a vida com o resultado do seu honesto trabalho. Finda 
a educação, como o Asilo não dispunha de nenhum outro dispositivo educativo interno, a trajetória de meninos e meninas diferia. Os meninos - considerados rapazes - eram entregues a mestres-de-ofício, Colégio dos Órfãos de São Joaquim, Companhias de Aprendizes Menores do Arsenal de Guerra ou da Marinha, fábricas da Província ou escolas práticas de agricultura. Já as meninas casavam-se, seguiam para a companhia de alguma família "capaz" ou deixavam a Casa para viverem por conta própria, quando do advento da maioridade.

Compreende-se o intuito da Casa em salvaguardar a vida e estabelecer condições satisfatórias de desenvolvimento para a criança. Mesmo assim, as constantes mudanças domiciliares impediam o desenvolvimento de um vínculo sadio com uma pessoa de referência. As possíveis trajetórias e circunstâncias de alocação da criança-traçadas conforme a disponibilidade ou das necessidades sociais - expressam um contexto de desenvolvimento voltado para o futuro da mesma, que, por vezes, não era partilhado pela mesma. Venâncio (1999) afirma que muitos expostos revoltavam-se com essa situação, permeada, em grande parte, por maus tratos, e fugiam dos estabelecimentos e, conseqüentemente, do controle e da guarda da Casa.

Já em 1914, o Asilo ficou mais responsável pelo desenvolvimento da criança. Esta permanecia no estabelecimento durante sua infância. Havia atividades, funcionários e espaços delimitados e específicos para as mesmas, de acordo com a sua faixa etária. De sua entrada até os três anos, a criança ficava na creche; dos três aos cinco anos, prosseguia para o jardim-deinfância; dos seis aos dez ou doze anos, estava inserida na escola primária; e, por fim, partia para o ensino técnico, para ambos os sexos, efetuado no próprio Asilo. Eventualmente, a criança podia ser encaminhada para um mestre-de-ofício (condição aparentemente masculina), bem como, apenas em casos extraordinários, decorrente de fraca condição de saúde, a criança saía do Asilo para ser criada por uma ama externa.

A creche não constituía um local de educação em si, mas um local de exercício dos cuidados higiênicos e morais da primeira infância. O jardim-de-infância adotava o sistema de educação Fröebel, no qual a criança era considerada uma planta débil e delicada, que necessitava de uma atenção perseverante. Devia-se atender ao desenvolvimento físico, intelectual e moral das crianças, habituando-as à ordem e ao asseio e estimulando o espírito, com exercícios dos sentidos e das faculdades de observação, e o corpo, com jogos ginásticos. A criança era vista como uma plantinha, que necessitava de cuidados especiais para florescer, como aponta Mattioli (1994).

O ensino primário era caracterizado por um ensino prático do português, aritmética, trabalhos manuais, ginástica e exercício físico, instrução moral, religiosa, cívica e cantos patrióticos. Os horários eram determinados e havia intermissões para recreio, no qual ainda se controlava e monitorava a atividade com ginástica e canto.

No ensino profissionalizante, permaneciam as características do ensino prático. Sua finalidade era dar aos internos a instrução técnica necessária para o desempenho de profissões, que possibilitassem o trabalho remunerado. Os cursos profissionalizantes eram divididos de acordo com o gênero masculino (marcenaria, sapataria, tornearia, dentre outros) e feminino (higiene e asseio pessoal e doméstico, costura, bordado). Buscava-se formar tanto homens capazes de ingressar no mercado de trabalho e de fabricar os necessários instrumentos da nascente economia industrial, quanto mulheres prendadas para o casamento e/ou que pudessem se sustentar por meio do próprio trabalho, inserindo-se em algum empreendimento considerado essencialmente feminino. Deve-se notar que as oficinas se encontravam na própria instituição. Suas instalações, porém, dependiam da demanda do mercado, a partir do reconhecimento da necessidade e da conveniência de cada uma delas.

Neste estatuto (de 1914), emergiram preceitos de higiene, prática, ordem e sustento próprio pela força de trabalho. Há declarada divisão da força de trabalho, com homens e mulheres ocupando espaços diferentes, além de 
enorme normatização dos comportamentos dos agentes sociais das instituições - tanto internos/ as quanto funcionários/as - deveriam seguir os parâmetros comportamentais traçados pela instituição. A disciplina pode ser ressaltada como fator normatizador e individualizante dos mesmos, a fim de obter cidadãos em conformidade com as normas sociais vigentes.

Vislumbra-se também, em ambos os estatutos, a existência de um sistema de tutoria da Santa Casa perante as/os internas/os e o Asilo dos Expostos como uma instituição temporária. Em 1863, entretanto, a tutela é parcial e representa a indicação da alocação da criança, em que o Asilo pode ser visto como local de passagem. Já em 1914, a tutela é estendida à completa guarda, com possibilidade maior de resguardo e controle dos/as internos/as, ao propiciar um ambiente mais controlado e, possivelmente, mais saudável, já que tanto as crianças quanto seus cuidadores estavam sob sua alçada direta e essa guarda prolongada permitia o melhor exercício do controle disciplinar, visando à reinserção social.

\section{Sistema de controle institucional}

Existia um sistema de controle institucional, tanto para os/as expostos/as quanto para os funcionários. Este pode ser compreendido como um sistema de auto-sustentação do estabelecimento e como medida em prol da segurança e do bem-estar da criança.

No caso dos funcionários, enfatizava-se, mais especificamente, o controle dos funcionários externos, em 1863, ou dos internos, em 1914. É constante, em ambos, a figura da Superioraresponsável pela disciplina, regime interno, fiscalização do estabelecimento e relatório dos eventos internos ao Mordomo dos expostos e ao Provedor da Casa. Essa figura caracterizava o controle centralizado.

Em 1863, os funcionários (externos) - amas e mestres-de-ofício - diante da retirada das crianças, assinavam um termo, prestavam "competente fiança", apresentavam fiador e se dispunham a levar os/as expostos/as para inspeção mensal (no caso dos mestres, em 1914 , isto não ocorre, pois a entrega do exposto significa entrega da guarda legalmente). Além disso, as amas seguiam com uma cópia do termo, o qual relatava as normas da Casa em relação ao cuidado infantil, ou seja, as medidas cautelares ou corretoras a aceitar e a seguir (visitas domiciliares "surpresas", supressão parcial ou total do pagamento mensal ou mesmo dispensa dos serviços).

Uma outra medida de controle de algumas mulheres, que expunham seus filhos para depois retirá-los como amas, consistia da não entrega de qualquer criança indicada pela ama. Esta medida de controle das amas está em concordância com o anunciado por Marcílio (1996), porém desconsidera o bem-estar do bebê, pois não possibilitava à ama permanecer com uma criança com a qual simpatizasse e pudesse, conseqüentemente, cuidar melhor.

De qualquer forma, essa prática de entrega dos próprios filhos pode denunciar duas tentativas de remediação da pobreza ou da dignidade, pelas quais mães recorrem à assistência de forma fraudulenta para manter os/as filhos/as, respectivamente, com o salário da Casa ou com a condição de ama - uma profissão - e, conseqüentemente, a legitimidade do "bastardo", via entrada institucional.

Em 1914, a única forma anunciada de controle dos funcionários externos eram as inspeções, mais numerosas e constantes. Havia, porém, controles constantes dos funcionários internos (médicos, cirurgiões-dentistas, mestres/as, professoras), já que suas atividades eram programadas e enumeradas, item por item, sendo ditado até o comportamento adequado, como no caso dos mestres-de-ofício, os quais deveriam desenvolver o ensino de forma prática e proveitosa, incutindo nos educandos o hábito da economia.

Essas medidas supracitadas buscavam (1) melhorar as condições de salubridade da criação (cuidadores, moradia, alimentação/ amamenta-ção, vestuário); e (2) eliminar procedimentos fraudulentos de (a) amas, que podiam 
receber expostos/as para vendê-los/as como escravos/as, findo o tráfico negreiro em 1850, ou não reportar as mortes das crianças à Casa, para continuar a receber os vencimentos pelos seus cuidados (Marcílio, 1996; Venâncio, 1999) e (b) mestres-de-ofício, que podiam fazer uso da mãode-obra gratuita e, muitas vezes, de maus tratos - daí a necessidade de tantas normas, inspeções e termos de responsabilidade.

As formas de controle da Casa em relação às/aos interna/os, especificamente, às expostas - pois estas permaneciam período mais longo na instituição - ocorriam segundo um sistema de recompensa e vigilância. Em ambos os estatutos, as visitas eram controladas, com a designação de dias específicos. Dotes eram concedidos apenas para casamentos ou saídas para viverem por conta própria aprovadas pela Mesa Administrativa da Casa. Em 1863, havia a concessão de prêmios às expostas que se sobressaíssem em qualquer área de ensino e de trabalho ou por seu comportamento exemplar. Em 1914, o comportamento exemplar possibilitava aos internos passeios supervisionados, pelos arrabaldes da cidade.

Em suma, a Casa possuía total controle dos/as expostos/as, exercendo grande pressão para normatização individual, sendo esta exercida diretamente pela concessão de benefícios somente aos comportamentos aprovados. Aspecto interessante é a não concessão de prêmios pelos trabalhos realizados, em 1914, mas $20 \%$ do valor líquido, fruto da venda dos produtos, eram endereçados a uma poupança para a exposta, valor este que podia ser retirado na saída da mesma. Parece existir um plano de preparação da interna para uma melhor (re)inserção social, ao menos financeira.

\section{CONSIDERAÇÕES FINAIS}

Os estatutos denunciam a construção progressiva de uma realidade sócio-histórica, baseada em preceitos filantrópicos, econômicos e higienistas, com especial consolidação no último estatuto. A preocupação com a sobre- vivência da criança exposta é substituída pela correta inserção social, como indivíduo moral, higiênico, disciplinado, trabalhador, produtor e conformado socialmente.

O contexto de desenvolvimento do Asilo dos Expostos - instituição de auxílio e proteção à infância - era marcado pela ambigüidade, como proposto por Sawaia (1999) e Chaves (2002). Se, por um lado, oferecia abrigo, alimentação, vestuário e educação, por outro, gerava uma inclusão social perversa, devido ao limitado período da própria institucionalização e de ser ou haver sido um/a exposto/a; e à pouca ou inexistente autonomia diante do processo decisório de seu futuro. O seu futuro estava intrinsecamente relacionado com as expectativas da Casa, quanto à melhor alocação social da criança, que nem como criança era considerada. Era, sim, um projeto de futuro - notoriamente diferenciado quanto às expectativas de seu gênero - visto como indivíduo útil a si e, principalmente, à sociedade. Sua força de trabalho (1) provia-lhe sustento, mas especialmente, anexava-o/a ao novo sistema comercial-marcado por eventos, dentre os quais a Lei do Ventre Livre, a Abolição da Escravatura, o início da industrialização e a Proclamação da República, carente de mão-deobra livre e capacitada; (2) dificultava o surgimento de marginais, mendigos e prostitutas, que ameaçavam a própria sociedade; e (3) gerava cidadãos essencialmente proletários.

A disciplina perpassava de forma crescente a vida dos/as expostos/as, via regulamentação das atividades, do sistema hierarquizado de controle e de recompensa e individualização dos agentes sociais, imbuindo-os das normas de socialização e indicando-lhes os possíveis caminhos a seguir, como denunciado por Foucault (1999).

A análise documental - como técnica qualitativa-e os documentos, especialmente os estatutos - por seu caráter de produção em tempo e por constituírem uma produção cultural dos valores e imagens socialmente aceitos - proporcionam elementos decisivos quanto à apreensão do contexto de desenvolvimento advogado, ao viabilizar a elucidação do contexto 
histórico e das práticas sociais. Tanto a História quanto a Psicologia adquirem importância nesse empreendimento, lançando luz sobre aspectos que poderiam passar despercebidos de outra forma, como apontam Ariès (1995) e Spink (2000). Mesmo assim, deve-se apontar as limitações do risco interpretativo na compreensão de dados modernos por contemporâneos que não vivenciaram o contexto histórico da época. Torna-se de suma importância, neste sentido, a submissão desse empreendimento ao diálogo com colegas, para discussões, as quais o presente artigo pretende endossar.

\section{REFERÊNCIAS BIBLIOGRÁFICAS}

ARIÉS, P. (1981). História social da criança e da família. Rio de Janeiro: Zahar.

(1995). A história das mentalidades. In: J. Le Goff. A história nova (p. 153-176). São Paulo: Martins Fontes.

BARDIN, L. (1994). Análise de conteúdo. Lisboa: Edições 70.

BENELLI, S.J. \& Costa-Rosa, A. (2002). A produção da subjetividade no contexto institucional de um seminário católico. Estudos de Psicologia, PUC-Campinas, 19, 2:19-58.

BRUNER, L. (1997). Atos de significação. Porto Alegre: Artes Médicas.

CARDOSO, C.F. \& Brignoli, H.P. (1990). Os métodos da história. Rio de Janeiro: Graal.

CHAVES, A.M. (2002). A vida e o viver em um internato: o ponto de vista de um grupo de meninos residentes. In: E.R. Lordelo; A.M.A. Carvalho, \& S.H. Koller (Orgs.) Infância brasileira e contextos de desenvolvimento ( $p$. 45-75). São Paulo: Casa do Psicólogo: Salvador: EDUFBA.
FOUCAULT, M. (1999). Vigiar e punir: o nascimento da prisão. Petrópolis: Vozes.

LE GOFF, J. (1995). A história nova. In: A história nova (p.25-64). São Paulo: Martins Fontes.

LOSICER, E. (1996). A pro-cura da subjetividade: a organização pede análise. In: E. Davel \& J. Vasconcelos (Orgs.). "Recursos" humanose subjetividade (p.68-79). Petrópolis: Vozes.

MERCÍLIO, M.L. (1996). Marginalidade, pobreza e abandono de crianças no Brasil: séculos XVIII e XIX. Revista de ciências históricas. Universidade Portucalense, 11: 163-173.

(1998). História social da criança abandonada. São Paulo: Hucitec.

MATTIOLI, O.C. (1994). Instituições de educação infantil: sua história e significado. Perfil: Boletim de Psicologia. 7: 41-58.

MINAYO, M.C.S. (1996). O desafio do conhecimento: pesquisa qualitativa em saúde. São Paulo: Hucitec; Rio de Janeiro: Abrasco.

PENNA, A.G. (1980). História das idéias psicológicas. Rio de Janeiro: Zahar Editores.

SAWAIA, B. (1999). Introdução: exclusão ou inclusão perversa? In: B. Sawaia (Org.). As artimanhas da exclusão: análise psicossocial e ética da desigualdade social (p. 5-13). Petrópolis: Vozes.

SPINK, P. (2000). Análise de documentos de domínio público. In: M.J. Spink (Org.) Práticas discursivas e produção de sentidos no cotidiano: aproximações teóricas e metodológicas (p. 123-151). São Paulo: Cortez.

VENÂNCIO, R.P. (1999). Famílias abandonadas: assistência à criança de camadas populares no Rio de Janeiro e em Salvador - séculos XVIII e XIX. Campinas: Papirus.

Recebido para publicação em 4 de setembro de 2003 e aceito em 5 de maio de 2004. 
